\title{
GENES CONFERRING ANTIMICROBIAL-RESISTANCE AMONG KLEBSIELLA PNEUMONIAE IN THE ARABIAN GULF COUNTRIES: A SYSTEMATIC REVIEW AND META-ANALYSIS
}

\author{
KHALID MUBARAK BINDAYNA ${ }^{1}$, RONNI MOL JOJI ${ }^{1 *}$, HICHAM EZZAT ${ }^{1}$, HAITHAM ALI JAHRAMI ${ }^{2}$
}

${ }^{1}$ Department of Microbiology, Immunology and Infectious Diseases, College of Medicine and Medical Sciences, Arabian Gulf University, Manama, Kingdom of Bahrain. ${ }^{2}$ Rehabilitation Services, Ministry of Health, Manama, Kingdom of Bahrain. Email: ronnimj@agu.edu.bh

Received: 20 January 2021, Revised and Accepted: 22 February 2021

\section{ABSTRACT}

Objective: The objective of the study was to look on the prevalence of six AMR genes (CTX-M, TEM, SHV, NDM-1, OXA-48, and VIM genes) in the province of the Arabian Gulf. We performed a systematic review and meta-analysis of the published studies from the Arabian Gulf countries and analyzed the antimicrobial resistance (AMR) genes pattern present in Klebsiella pneumoniae.

Methods: The present study used the Meta-analysis Of Observational Studies in Epidemiology as a guideline for reporting findings. An electronic search was conducted in online databases such as PubMed/MEDLINE, EMBASE, Scopus, Google Scholar, Science Direct, and Web of Science from January 2014 to June 2020 following the inclusion and exclusion criteria. Articles published were included in the study resistance pattern among 2036 isolates were analyzed. These isolates conferred the AMR genes including OXA-48 ( $n=500)$, CTX-M ( $n=1796)$, SHV ( $n=1637)$, TEM ( $n=1492)$, NDM-1 $(\mathrm{n}=500)$, and VIM $(\mathrm{n}=302)$.

Results: Of 160 initially searched studies, 28 entries met the inclusion criteria and were subjected to meta-analysis. Critical appraisal of studies or quality assessment revealed a mean quality score was 4.2 , with an SD of 1.6. The analysis revealed predominant AMR genes wereOXA-48 followed by CTX-M, SHV, TEM, NDM-1, and VIM in the Arabian Gulf region.

Conclusion: The Arabian Gulf countries share a high prevalence of OXA-48, CTX-M followed by SHV, TEM, NDM-1, and VIM genes. Antimicrobialresistant in K. pneumoniae is a threat to public health and this needs strong surveillance to curb this threat.

Keywords: Antimicrobial resistance genes, Arabian Gulf region, Klebsiella pneumoniae, Meta-analysis, Systematic review.

(C) 2021 The Authors. Published by Innovare Academic Sciences Pvt Ltd. This is an open access article under the CC BY license (http://creativecommons.org/ licenses/by/4.0/) DOI: http://dx.doi.org/10.22159/ajpcr.2021v14i4.40841. Journal homepage: https://innovareacademics.in/journals/index.php/ajpcr

\section{INTRODUCTION}

Klebsiella is one of the common pathogens causing communityacquired bacterial pneumonia, urinary tract infection, and septicemia in patients. If untreated, it can lead to a high mortality rate [1,2]. A vast majority of Klebsiella infections are hospital-acquired. Individuals with underlying diseases such as diabetes mellitus or chronic pulmonary obstruction or other immunocompromised states can acquire Klebsiella as a nosocomial infection [1]. In fact, Klebsiella has been reported as the second most common cause of bacteremia in patients with burns [3]

It is a challenge to treat Klebsiella clinically. Bacteria have developed effective defense mechanisms against most of the antibiotics [4]. Multidrug resistance is reported in Klebsiella since 1984 [3]. Klebsiella has become resistant to beta-lactam drugs, including cephalosporins and aminoglycosides due to its ability to encode extended-spectrum $\beta$-lactamases (ESBLs) and aminoglycoside modifying enzymes [3]. An increase in antimicrobial resistance (AMR) in Klebsiella pneumonia isolates is of much concern.

The CDC estimates that within the United States, quite 2 million people are diseased with antibiotic-resistant microorganisms annually. Among them, around 23,000 die every year [5]. Several factors can contribute to the spread of AMR, including inappropriate antibiotic use in the health-care sectors and agriculture and lack of new antimicrobial therapeutics $[5,6]$. Continuous exposure of bacterial strains to multiple $\beta$-lactam drugs has induced dynamic and continuous production and mutation of $\beta$-lactamases. It has even increased its activity against the newly developed $\beta$-lactam antibiotics which are known as ESBLs [7].
The occurrence of ESBL producing Enterobacteriaceae is also reported in human and veterinary medicine [8].

Several studies have addressed increased AMR rates among bacterial organisms in the Arabian Gulf Region. They have reported multiple factors that might be contributing to the increasing AMR rates [9].

The prevalence of AMR genes has severe implications for the future therapy and prevention of infectious diseases in humans. Studies have identified multiple genes to be associated with AMR in the Arabian Gulf region. However, there are no comprehensive reviews of these studies. This article aims to review the occurrence of six AMR genes (CTX-M, TEM, SHV, NDM-1, OXA-48, and VIM genes) in the Arabian Gulf region. We conducted a systematic review and meta-analysis of the studies reporting the presence of AMR genes in K. pneumoniae, published from the Arabian Gulf region.

\section{METHODS}

The present study used the "Meta-analysis Of Observational Studies in Epidemiology (MOOSE)" guidelines for reporting findings [10].

\section{Database searches}

We conducted an electronic search in seven online databases PubMed/MEDLINE, EMBASE, Scopus, Google Scholar, Science Direct, and Web of Science for articles published between January 2014 and September 2019. The search strategy included relevant keywords: "Klebsiella pneumoniae" OR "Enterobacteriaceae" OR "antimicrobial resistance" OR "antibiotic resistance" OR "drugresistance" OR "Eastern Mediterranean" OR "The Middle East" OR "antimicrobial resistance" OR "antibiotic resistance" OR "drug- 
resistance" OR "Gulf Co-operation Council (GCC)" OR "Saudi Arabia (KSA)" OR "Bahrain" OR "Kuwait" OR "Oman" OR "United Arab Emirates (UAE)" OR "Qatar" OR "resistant genes" AND "ExtendedSpectrum Beta-Lactamase (ESBL)" OR "Metallobeta-lactamase (MBL)" OR “CTX-M" OR "NDM-1 OR "OXA-48" OR "TEM" OR "VIM" OR "SHV."

Two authors independently reviewed the titles and abstracts and chose those fitting the selection criteria for full-text evaluation and excluded irrelevant publications. Any discrepancies regarding study eligibility were discussed with other authors to reach a consensus. To standardize data extraction, the reviewers collected data for study characteristics (e.g., type of bacterial isolates, country, year, sample size, and type of antibiotic-resistant genes). Extracted data were entered into Microsoft Excel Sheet for analysis.

\section{Inclusion criteria}

We included observational studies and intervention studies reporting the presence of any of the selected six AMR genes in clinical strains of K. pneumoniae.

Inclusion criteria for study selection were:

- All original research articles published in the English language

- Publication date between January 2014 to June 2020

- Studies that included K. pneumoniae clinical isolates

- Studies that reported AMR genes from Arabian Gulf countries.

- Articles reporting resistant genes detection by molecular methods (PCR).

\section{Exclusion criteria}

The following criteria were excluded from the study:

- Studies conducted on K. pneumoniae strains from environmental resources such as food, water, and air

- Studies reporting secondary data

- Studies on other AMR genes that are not included in the selection criteria

- Studies reporting resistance genes by phenotypic methods

- Case reports, short communications, abstracts, review articles, editorials, and non-English-language articles

- Unpublished, non-peer-reviewed data, all of which were excluded from the quantitative and qualitative analysis.

If more than one article is published from a single study, the results are combined, and the studies are considered only once for analysis. The flow diagram of study selection is shown in Fig. 1.

\section{Primary outcome}

The primary outcome of this review is the prevalence of six AMR genes (CTX-M, NDM-1, OXA-48, TEM, VIM, and SHV) in Klebsiella isolates from patients in the Arabian Gulf region.

\section{Critical appraisal of studies (quality assessment)}

Two reviewers independently assessed the methodological quality of studies using a standardized checklist consisting of six items. The items included sample size, sampling technique, standardization of data collection, appropriateness of statistical analyses, quality of reporting results, and generalizability. The appraisal scores range between zero
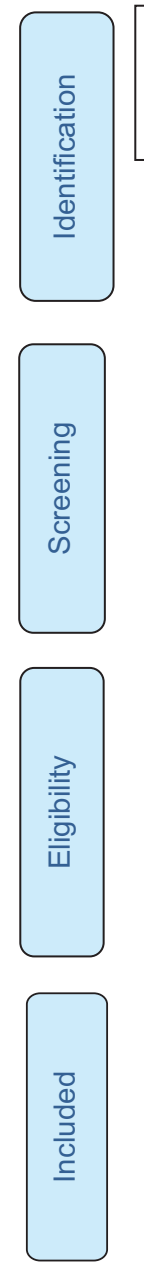
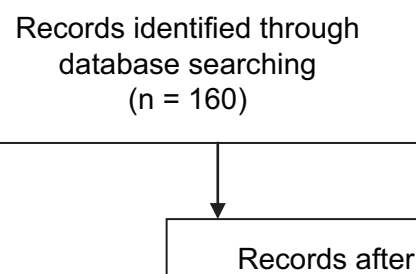

Records after duplicates removed $(n=60)$

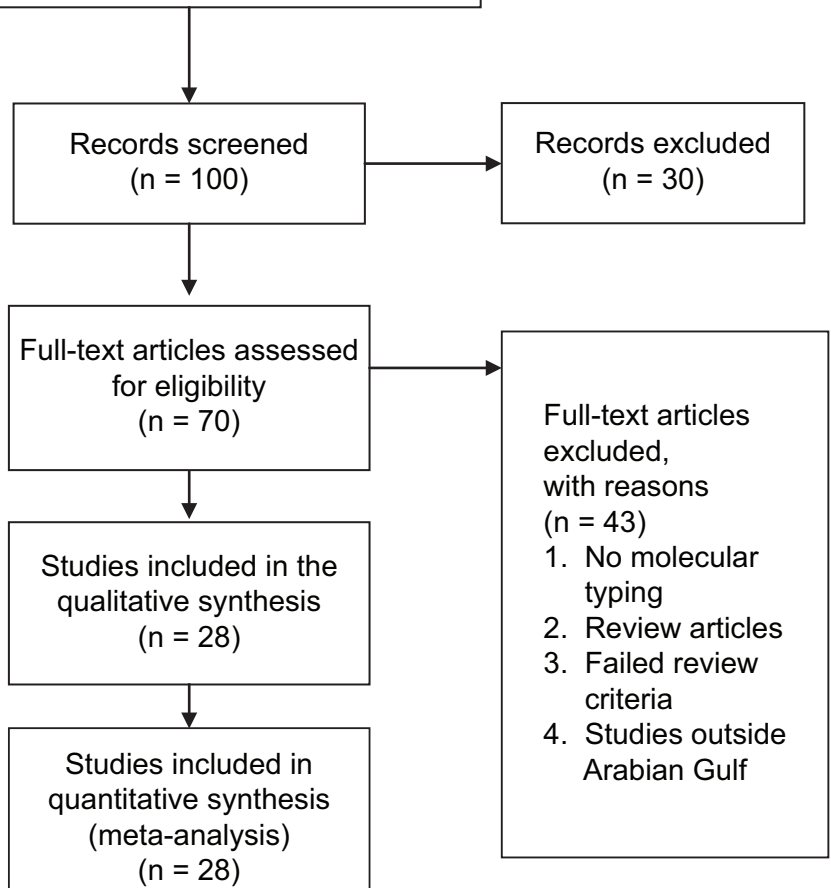

Fig 1. The stages of evaluation and exclusion of the included studies
Additional records identified through other sources $(n=0)$ 
and six were given. A score of 0-2 corresponds to low quality, 3-4 to medium quality, and 5-6 to high quality. If there was a discrepancy, the quality score was assigned for each study by consensus of all authors after discussion with the principal investigator. We used the NewcastleOttawa Scale as a guide for assessing the quality of nonrandomized studies in meta-analysis [11]

\section{Statistical analysis and reporting}

We performed a series of single-group analysis based on sample size and event rate. We used Random-effects modeling in the analysis. Using random-effects modeling, we, therefore, assume that there is not only one true effect size, instead, a distribution of true effect sizes. We, therefore, sought to estimate the mean of the distribution of true effect sizes. Moderator analysis was performed on the variable country and was performed using subgroup analyses. All statistical analyses were performed using the Comprehensive Meta-Analysis version 3.0.

\section{RESULTS}

Of 160 initially searched studies, 28 entries met the inclusion criteria and were subjected to a meta-analysis [12-38]; the stages of evaluation and exclusion of the identified studies were as per the inclusion chart is presented in Fig. 1. Study characteristics (e.g., authors, country, year, sample size, patient location, and type of antibiotic-resistant genes) are represented in Table 1.

Critical appraisal of studies or quality assessment revealed mean quality score was 4.2 , with an S.D. of 1.6; indicating that studies were generally of medium quality.
The most common resistance genes reported are OXA-48, followed by CTX-M, SHV, TEM, NDM-1, and VIM. The prevalence of OXA48 is $61.3 \%$ and CTX M is $49.9 \%$, followed by SHV (46.1\%), TEM (32.5\%), NDM-1 (26.9\%), and VIM (6.1\%). Detailed results of the point estimate, the $95 \% \mathrm{CI}$, and measures of heterogeneity are shown in Table 2. Forest plots of the meta-analysis are presented in Figs. 2-7.

\section{Subgroup analysis}

The subgroup analysis of the different AMR genes was conducted by country in which studies were done (Fig. 2-7). As can be seen, by the forest plots, OXA- 48 gene was studied exclusively in Saudi Arabia. of the eight studies that have studied the OXA-48 gene, six of them reported point prevalence of the gene to be more than $0.5 \%$. The mean point prevalence was $65.1 \%$ (Fig 2).

CTX-M gene was studied by two studies from Kuwait, studies from Qatar, 15 studies from Saudi Arabia, and two studies from UAE. The prevalence of the gene was highest in UAE (93.6\%), followed by Kuwait (56.4\%) and Saudi Arabia (49.1\%). Studies from Qatar reported the least prevalence (6.6\%) (Fig 3).

SHV gene was also studied by all four countries. Thirteen studies were from Saudi Arabia, while two studies were from each of UAE, Kuwait, and Qatar. The point prevalence of the gene was similar in distribution to the CTX-M gene with maximum prevalence in UAE (85.2\%), followed by Kuwait (59.1\%), Saudi Arabia (46.8\%), and Qatar (7.7\%) (Fig. 4)

Table 1: Study characteristics

\begin{tabular}{|c|c|c|c|c|c|c|c|c|c|}
\hline Authors & Country & Patient location & Sample size & OXA-48 & CTX -M & SHV & TEM & NDM-1 & VIM \\
\hline Al-Qahtani et al. (2014) [19] & Saudi Arabia & Hospital & 98 & & 32 & 34 & 20 & & \\
\hline Jamal et al. (2013) [16] & Kuwait & $\begin{array}{l}\text { Medical and surgical } \\
\text { ward, ICU }\end{array}$ & 9 & & 4 & 7 & 5 & 3 & 6 \\
\hline Jamal et al. (2016) [31] & Kuwait & Public hospitals & 14 & & 9 & 6 & & 14 & \\
\hline Al-Zahrani et al. (2018) [12] & Saudi Arabia & Province hospitals & 54 & 44 & & & & 4 & 1 \\
\hline AlTamimi et al. (2017) [13] & Saudi Arabia & $\begin{array}{l}\text { Inpatients and } \\
\text { outpatients }\end{array}$ & 34 & 18 & & & & 4 & 1 \\
\hline Sonnevend et al. (2015) [15] & Arabian Peninsula & Inpatients & 145 & 43 & & & & 78 & 6 \\
\hline Eltai et al. (2018) [17] & Qatar & Pediatric patients & 13 & & 0 & 0 & 0 & & \\
\hline Elhassan et al. (2016) [18] & Saudi Arabia & $\begin{array}{l}\text { Inpatients and } \\
\text { outpatients }\end{array}$ & 359 & & 6 & 9 & 8 & & \\
\hline Alsultan et al. (2013) [20] & Saudi Arabia & $\begin{array}{l}\text { Inpatients and } \\
\text { outpatients }\end{array}$ & 37 & & 0 & 29 & 16 & & \\
\hline Ahmed et al. (2016) [21] & Qatar & ICU & 629 & & 42 & 49 & 30 & & \\
\hline Alfaresi et al. (2018) [22] & United Arab Emirates & General Hospital & 5 & & 5 & 4 & 5 & & \\
\hline Hassan et al. (2013) [24] & Saudi Arabia & $\begin{array}{l}\text { Inpatients and } \\
\text { outpatients }\end{array}$ & 90 & & 82 & 77 & 43 & & \\
\hline Leangapichart et al. (2016) [25] & Saudi Arabia & Adults & 1 & & & & 1 & & \\
\hline Leangapichart et al. (2016) [25] & Saudi Arabia & Adults & 5 & & 5 & 4 & 4 & & \\
\hline Soliman et al. (2018) [26] & Saudi Arabia & $\begin{array}{l}\text { Inpatients and } \\
\text { outpatients }\end{array}$ & 33 & & 13 & 12 & 0 & & \\
\hline Somily et al. (2015) [27] & Saudi Arabia & $\begin{array}{l}\text { Inpatients and } \\
\text { outpatients }\end{array}$ & 27 & & 23 & 16 & 1 & & \\
\hline Sonnevend et al. (2017) [28] & United Arab Emirates & Adult & 9 & & 9 & 8 & 8 & & \\
\hline Uz Zaman et al. (2014) [29] & Saudi Arabia & Patients & 23 & 23 & 23 & 23 & 22 & & \\
\hline Alsheikh et al. (2014) [30] & Saudi Arabia & Patients & 92 & & 9 & 0 & 44 & & \\
\hline Al-agamy et al. (2013) [32] & Saudi Arabia & Patients & 9 & 7 & 8 & 9 & & 2 & \\
\hline Zowawi et al. (2014) [33] & Saudi Arabia & Hospital & 147 & 34 & 48 & & & 10 & \\
\hline Alotaibi et al. (2017) [34] & Saudi Arabia & Inpatients & 5 & 1 & & & & 3 & \\
\hline Al-Agamy et al. (2018) [35] & Saudi Arabia & Hospitals & 21 & 14 & 19 & & & 7 & \\
\hline Ahn et al. (2015) [36] & United Arab Emirates & ICU & 2 & 2 & & & & 0 & \\
\hline Shahid (2014) [37] & Bahrain & Adult patients & 5 & & 5 & & & & \\
\hline
\end{tabular}

*Empty field: Not reported, ICU: Intensive care unit 


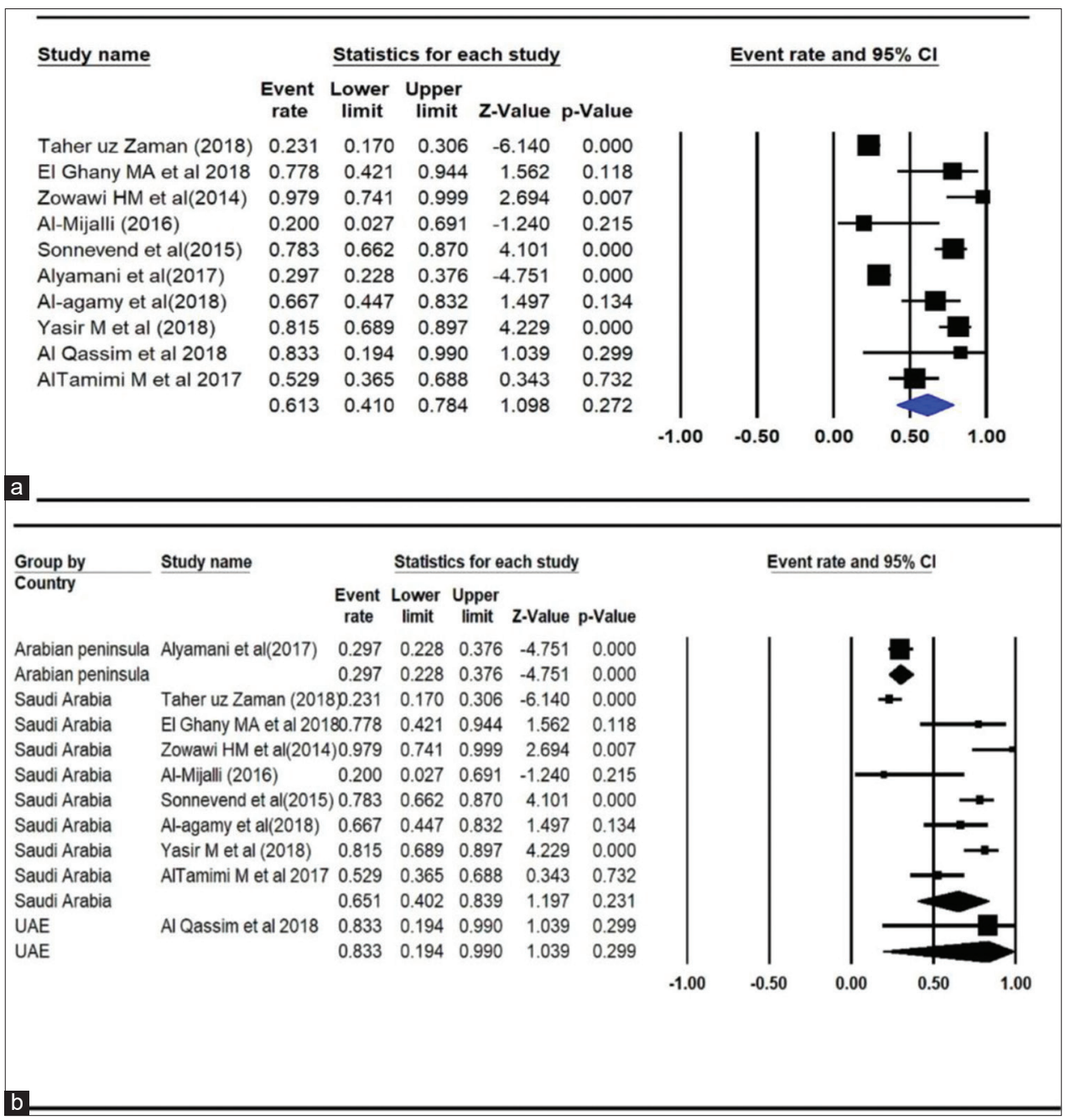

Fig. 2: Klebsiella OXA-48 gene. (a) Meta-analysis results. (b) Subgroup (by country) meta-analysis results

Table 2: Prevalence of antimicrobial resistance genes

\begin{tabular}{|c|c|c|c|c|c|c|}
\hline Parameters & OXA-48 & CTX-M & SHV & TEM & NDM-1 & VIM \\
\hline Number of studies (K) & 10 & 22 & 19 & 16 & 11 & 5 \\
\hline Number of isolates $(\mathrm{N})$ & 500 & 1796 & 1637 & 1492 & 500 & 302 \\
\hline Proportion & $61.3 \%$ & $49.9 \%$ & $46.1 \%$ & $32.5 \%$ & $26.9 \%$ & $6.1 \%(1.1-28.2 \%)$ \\
\hline$(95 \% \mathrm{CI})$ & $(41-78.4 \%)$ & $(31.1-68.8 \%)$ & $(25.6-68 \%)$ & $(17.2-52.8 \%)$ & $(13.5-46.5 \%)$ & \\
\hline Q-value & 102.938 & 416.089 & 418.179 & 265.348 & 93.550 & 28.150 \\
\hline $\mathrm{Df}(\mathrm{Q})$ & 9 & 21 & 18 & 15 & 10 & 4 \\
\hline $\mathrm{p}$ & 0.000 & 0.000 & 0.000 & 0.000 & 0.000 & 0.000 \\
\hline $\mathrm{Tau}^{2}$ & 1.330 & 2.869 & 3.475 & 2.318 & 1.627 & 3.475 \\
\hline
\end{tabular}

CI: Confidence interval, Q-value: Cochran's Q Df: A degree of freedom, I²: A measure of variability between studies, P: P value, Tau²: Variance of the two effect sizes

There were no studies on the TEM gene from Kuwait. There were two studies from each of Qatar and UAE while 11 studies were from Saudi Arabia. The prevalence of the gene was highest in the UAE (89.9\%), while it was 30.5\% in Saudi Arabia and $4.7 \%$ in Qatar (Fig. 5).

Two studies from Kuwait and seven studies from Saudi Arabia studied the NDM-1 gene. The point prevalence of the gene was $75.5 \%$ in Kuwait. However, the studies differed significantly in their estimation of the prevalence, and the mean confidence interval was broad. Studies from Saudi Arabia reported a prevalence of $4.7 \%$ (Fig. 6).
VIM gene was studied exclusively in Saudi Arabia. Only three studies reported studying the VIM gene. The mean point prevalence of the gene was $2.1 \%$ (Fig. 7 ).

\section{DISCUSSION}

$K$. pneumoniae is a pathogen known for its resistance to most of the antibiotics used. The increasing trends in the isolation of antimicrobial-resistant K. pneumoniae are of much concern [6]. K. pneumoniae have acquired carbapenemases, which are capable of breaking down most $\beta$-lactams, including carbapenems, and confer resistance to these drugs. Reports indicate that carbapenemase- 


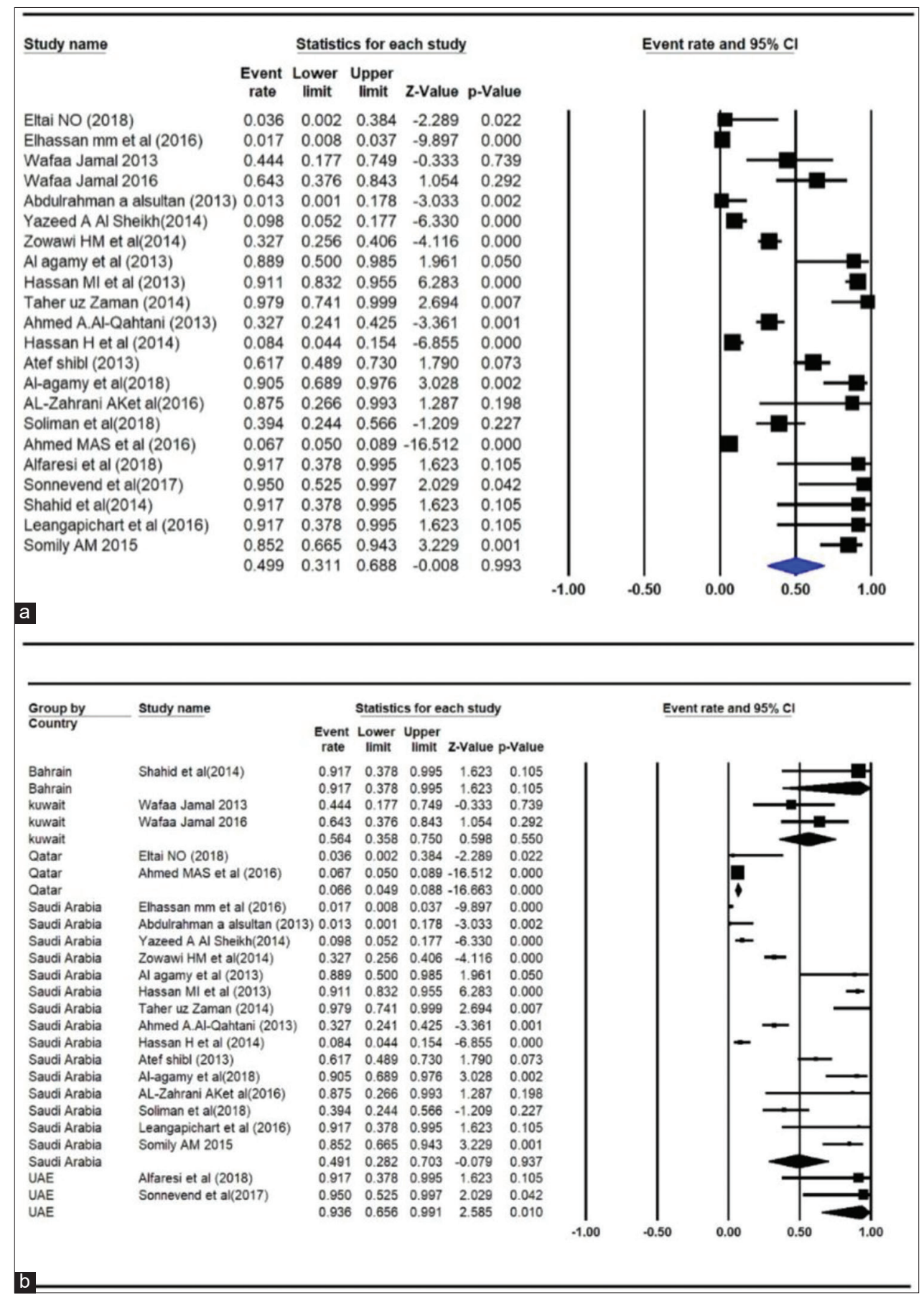

Fig. 3: Klebsiella CTX-M gene. (a) Meta-analysis results. (b) Subgroup (by country) meta-analysis results

producing Enterobacteriaceae isolates are increasing in number in the last few years [39].

In this study, the OXA-48 (61.3\%) is seen to be the most predominant antimicrobial gene in the Arabian Gulf Region. OXAKp isolates are detected worldwide. The first description of isolates with OXA-48 like genes was reported in 2013 in the United States [40]. A study from China has reported $14.9 \%$ of the clinical isolates of K. pneumoniae with OXAKp [41]. In a study from India, significantly, $80 \%$ of their isolates were blaOXA-232 producers [42]. A study from Turkey reported $86 \%$ of their isolates harbored the OXA-48 gene [43]. The high prevalence of OXA-48 in the Arabian Gulf reflects the extensive flow between the countries of the Middle East and endemic countries including Turkey, India, and Pakistan[12].

CTX-M enzymes are Class A ESBLs that are spreading rapidly among Enterobacteriaceae worldwide [44]. In our study analysis, the CTX-M gene (49.9\%) was the next predominant gene persistent in clinical isolates. No CTX-M was detected in the U.S. before 2000 among ESBL-producing K. pneumoniae isolates, with all CTX-Mproducing K. pneumoniae isolates recovered from U.S. patients in or after 2004 [45]. The emergence and spread of CTX-Min K. pneumoniae have evolved recently in the mid to late 2000s in the United States. To date, CTX-M-producing K. pneumoniae has been recognized in several U.S. states, including Texas, Nebraska, 


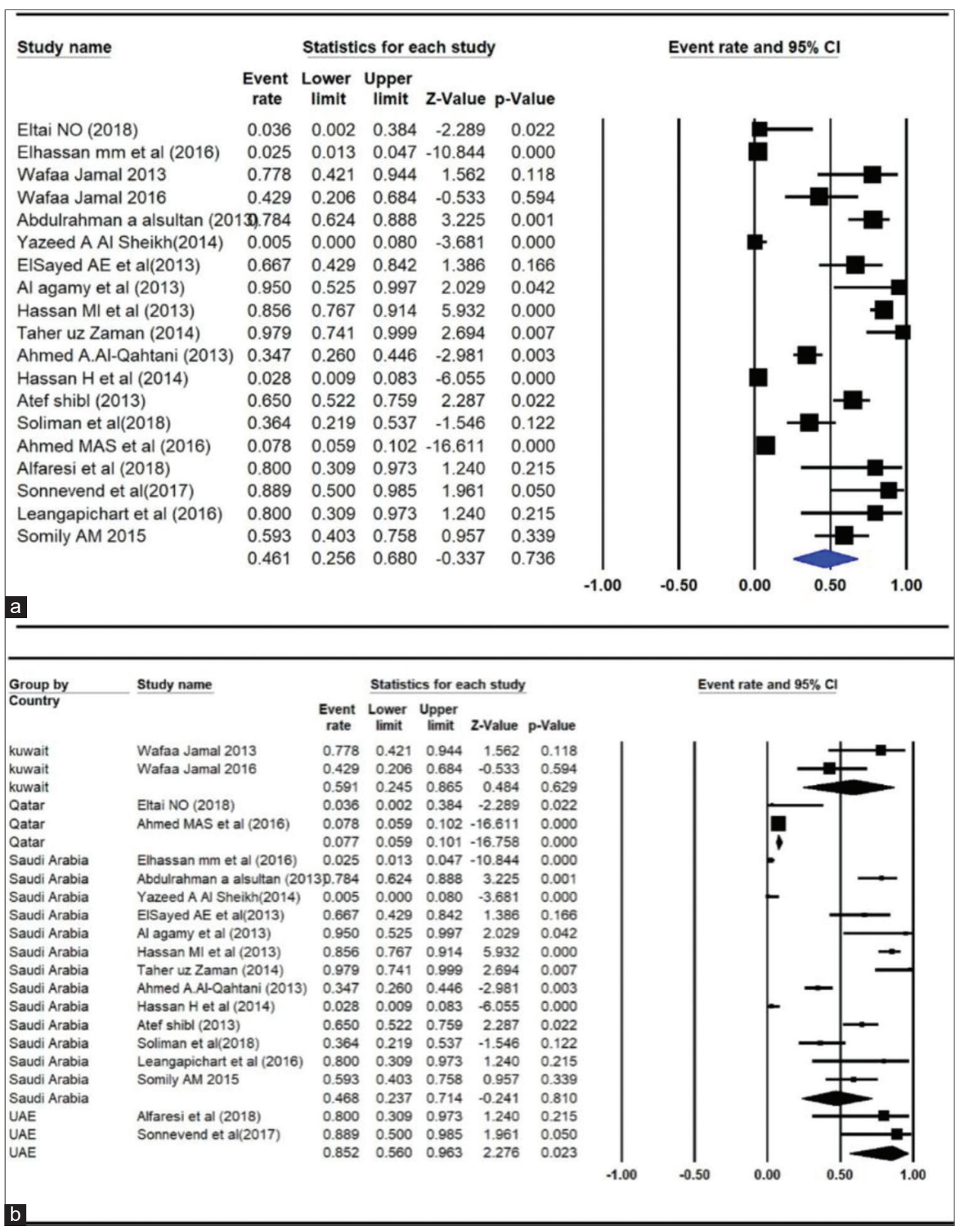

Fig 4: Klebsiella SHV gene. (a) Meta-analysis results. (b) Subgroup (by country) meta-analysis results

Pennsylvania, California, Massachusetts, Michigan, New Jersey, New York, Washington, and Wisconsin [46]. Jemima and Verghese reported the presence of CTX-M genes in $40 \%$ of Klebsiella spp. [47]. Another study in India by Sekar et al. reported the prevalence of the CTX-M gene in $35.89 \%$ of Gram-negative isolates [48]. The presence of the CTX-M gene is worrisome as the plasmids carrying this determinant has also the ability to seize other resistance determinants, including carbapenemases genes [49], and thus spread multidrug resistance.

In the present analysis, the SHV gene was present in $46.1 \%$, TEM in $32.5 \%$, and the carbapenem-resistant genes - NDM-1 in $26.9 \%$ and VIM in $6.1 \%$ of the total studies. Al-Qahtani et al. in Saudi Arabia reported the presence of SHV-12 (29.73\%) and SHV-5 (5.4\%) and TEM (54.05\%). A study in Kuwait observed a high prevalence of VIM$4(66.6 \%)$, followed by NDM-1 (33.3\%) and SHV-11 (55.5\%), SHV-
31 (11.1\%), and SHV-26 (11.1\%). Interestingly, they also reported OKP type in K. pneumoniae which is a variant of naturally occurring SHV-type enzymes. This suggests wide dissemination of the genes throughout Arabian countries [16]. Some studies have reported the co-existence of MBLs and ESBLs in the enterobacterial isolates $[16,50]$. Treatment of patients infected with these multi-resistant infectious agents is challenging.

Globally, Greece has the highest rate of reported carbapenem resistance (68\%) followed by India and eastern Mediterranean regions with 54\% resistance. USA (11\%), China (11\%), and Africa (4\%) have the lowest resistance rates, respectively [40]. Dehshiri et al. in Iran demonstrated the presence of the genes TEM (16.1\%), and SHV (85.5\%) among the K. pneumoniae isolates from urine samples [51], while in India, among the ESBLs, SHV, TEM, and CTX-M have been commonly reported by Veeraraghavan et al. [52]. In China, 


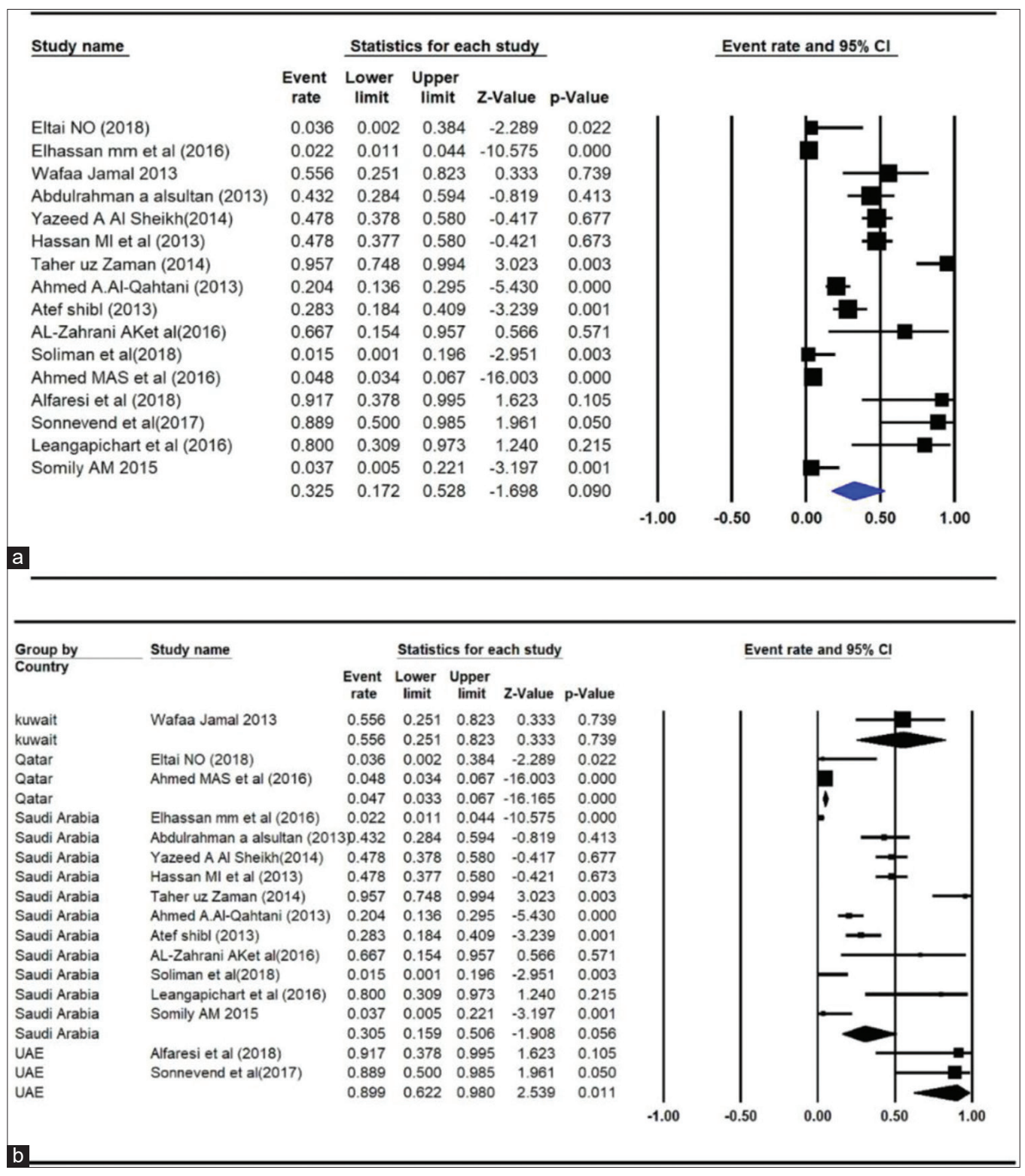

Fig. 5: Klebsiella TEM gene. (a) Meta-analysis results. (b) Subgroup (by country) meta-analysis results

Zhang et al. reported NDM-1 producing $K$. pneumoniae isolates in the neonatal ward of a teaching hospital [53]. Liu et al. reported four diverse types (NDM-1, KPC-2, VIM-2, and IMP-4) of carbapenemase of $K$. pneumoniae clones in a single hospital in China [54]. The VIM gene is extensively distributed worldwide, with VIM-2 the most widespread variant. VIM enzyme endemicity has been reported in Greece, Taiwan, and Japan, and outbreaks and single strains of VIM producers have been stated in many other countries including México, Argentina, Colombia, and Venezuela [55]. VIM-1-producing Enterobacteriaceae have been associated with single cases, small outbreaks, or polyclonal spread affecting different species of bacteria in Spain [11].

As can be seen from the subgroup analysis, the maximum number of studies was conducted in Saudi Arabia, while the other three countries had near equal representation. Some genes (OXA-48 \& VIM) were studied exclusively in Saudi Arabia. One of the reasons for the same can be the country size and the drive for research. The population of Saudi Arabia is nearly 16 times that of Qatar, more than 8 times Kuwait, and more than 3 times the population of the UAE. Furthermore, Saudi Arabia is a forerunner in the research front and has an active and zealous research community. This might have manifested in maximum representation from the country.

However, all four countries are in geographic continuity and share similar demography, environment, disease epidemiology, and even cultural practices. The differences observed in the prevalence of different AMR genes might be due to the differences in the number of studies and the sample sizes than true prevalence. For the same reason, the results of the study can be generalized to other gulf countries.

Overall, Arabian Gulf Countries are more susceptible to multidrug infections including carbapenem-resistant genes. This is mainly due to the high resident expatriate population (average 48\%), extensive international links, lack of clear guidelines on antimicrobial use, and deficiency of policies for containing and reviewing antimicrobial prescriptions [15]. 


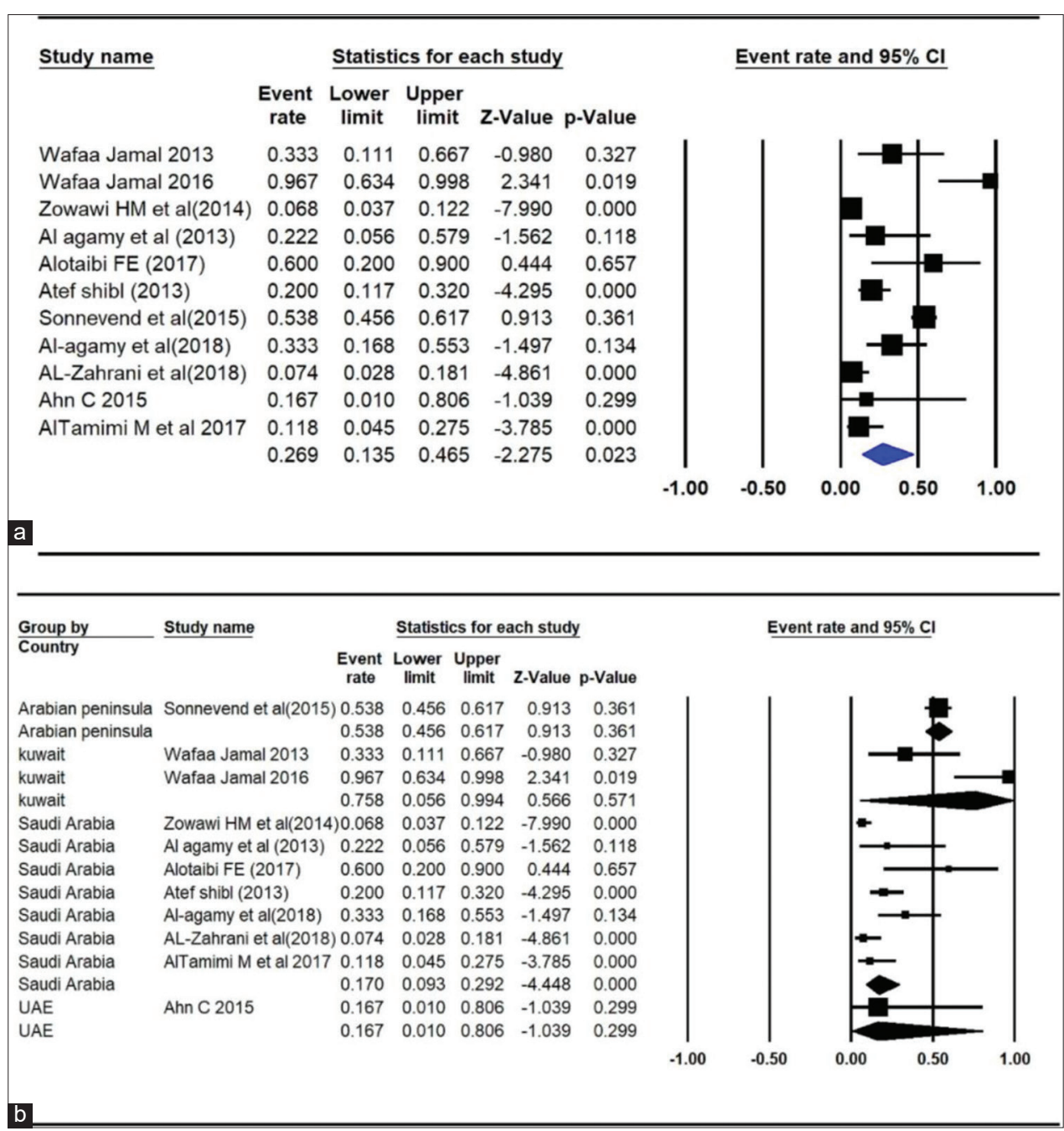

Fig. 6: Klebsiella NDM-1 gene. (a) Meta-analysis results. (b) Subgroup (by country) meta-analysis results

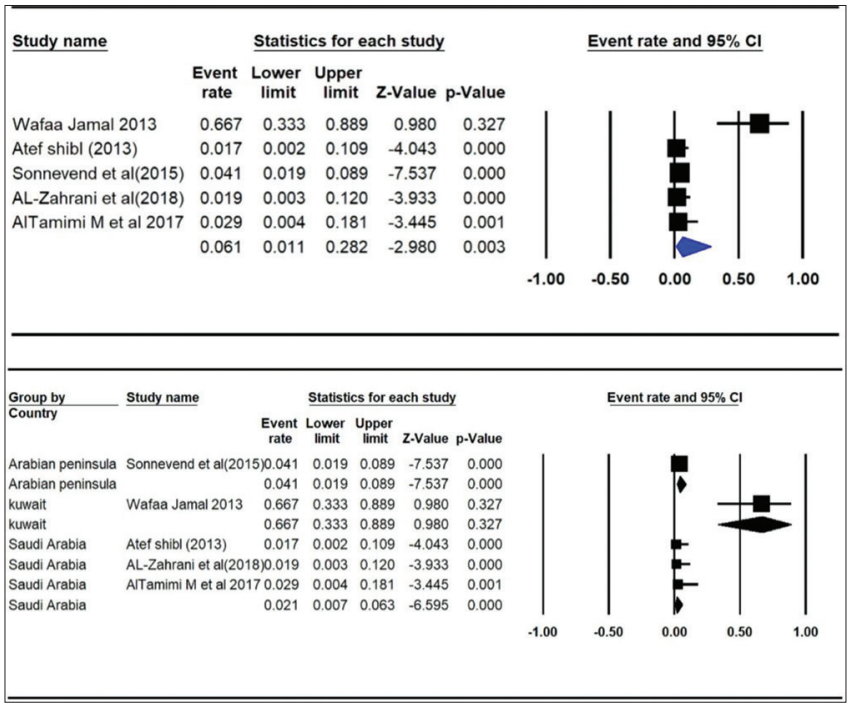

Fig. 7: Klebsiella VIM gene. (a) Meta-analysis results. (b) Subgroup (by country) meta-analysis results

\section{CONCLUSION}

The antibiotic resistance gene prevalence's of $K$. pneumoniae in countries of the Arabian Gulf, namely, Saudi Arabia, Bahrain, Kuwait,
United Arab Emirates, Oman, and Qatar, have been critically reviewed in this study. These countries share a high prevalence of OXA, CTX-M followed by SHV, TEM, NDM, and VIM genes. Antimicrobial-resistant in $K$. pneumoniae is a threat to public health, and this needs robust surveillance to curb this menace. Health-care sectors need to monitor and report changes in antimicrobial-resistant isolates. A multifactorial approach, including standard guidelines, and appropriate infection control measures is necessary to curb this threat.

\section{AUTHORS CONTRIBUTION}

Khalid Bindayna designed the study. Ronni Joji, Khalid Bindayna coordinated data search, data entry, and data cleaning. Haitham performed the statistical analysis. Ronni Joji wrote the first draft and Khalid Bindayna, Hicham Ezzat provided intellectual contributions to strengthening the manuscript. All authors provided critical revisions of the manuscript and approved the final version.

\section{CONFLICT OF INTEREST}

Nil.

\section{AUTHORS FUNDING}

None.

\section{REFERENCES}

1. Podschun R, Ullmann U. Klebsiella spp. as nosocomial pathogens: Epidemiology, taxonomy, typing methods, and pathogenicity factors. 
Clin Microbiol Rev 1998;11:589-603.

2. Magill SS, Edwards JR, Bamberg W, Beldavs ZG, Dumyati G, Kainer MA, et al. Multistate point-prevalence survey of health careassociated infections. N Engl J Med 2014;370:1198-208.

3. Piruozi AF, Farahani A, Forouzandeh Z, Ahmadi I, Abdizadeh R, Kalantar M, et al. Investigating the frequency of Klebsiella infection and drug resistance among inpatients and outpatients referring to Amir Al-Momenin Hospital, Gerash, Iran. Gene Cell Tissue 2019;6:e93161.

4. Munita JM, Arias CA. Mechanisms of antibiotic resistance. Microbiol Spectrum 2016;4:1128

5. Centers for Disease Control and Prevention. Antibiotic Resistance Threats in the United States, 2013. Atlanta: Centers for Disease Control and Prevention; 2014.

6. Effah CY, Sun T, Liu S, Wu Y. Klebsiella pneumoniae: An increasing threat to public health. Ann Clin Microbiol Antimicrob 2020;19:1.

7. Sarojamma V, Ramakrishna V. Prevalence of ESBL-producing Klebsiella pneumoniae isolates in tertiary care hospital. ISRN Microbiol 2011;2011:318348.

8. Daehre K, Projahn M, Friese A, Semmler T, Guenther S, Roesler UH. ESBL-producing Klebsiella pneumoniae in the broiler production chain and the first description of ST3128. Front Microbiol 2018;9:2302.

9. Al-Tawfiq JA, Stephens G, Memish ZA. Inappropriate antimicrobial use and potential solutions: A Middle Eastern perspective. Expert Rev Antiinfect Ther 2010;8:765-74

10. Stroup DF, Berlin JA, Morton SC, Olkin I, Williamson GD, Rennie D, et al. Meta-analysis of observational studies in epidemiology: A proposal for reporting. Meta-analysis of observational studies in epidemiology (MOOSE) group. JAMA 2000;283:2008-12.

11. Sánchez-Romero I, Asensio Á, Oteo J, Muñoz-Algarra M, Isidoro B, Vindel A, et al. Nosocomial outbreak of VIM-1-producing Klebsiella pneumoniae isolates of multilocus sequence Type 15: Molecular basis, clinical risk factors, and outcome. Antimicrob Agents Chemother 2012;56:420-7.

12. Al-Zahrani IA, Alsiri BA. The emergence of carbapenem-resistant Klebsiella pneumoniae isolates producing OXA-48 and NDM in the Southern (Asir) Province, Saudi Arabia. Saudi Med J 2018;39:23-30.

13. AlTamimi M, AlSalamah A, AlKhulaifi M, AlAjlan H. Comparison of phenotypic and PCR methods for detection of carbapenemases production by Enterobacteriaceae. Saudi J Biol Sci 2017;24:155-61.

14. Shibl A, Al-Agamy M, Memish Z, Senok A, Khader SA, Assiri A. The emergence of OXA-48- and NDM-1-positive Klebsiella pneumoniae in Riyadh, Saudi Arabia. Int J Infect Dis 2013;17:e1130-3.

15. Sonnevend A, Ghazawi AA, Hashmey R, Jamal W, Rotimi VO, Shibl AM, et al. Characterization of carbapenem-resistant Enterobacteriaceae with high rate of autochthonous transmission in the Arabian Peninsula. PLoS One 2015;10:e0131372.

16. Jamal W, Rotimi VO, Albert MJ, Khodakhast F, Nordmann P, Poirel L. High prevalence of VIM-4 and NDM-1 metallo-betalactamase among carbapenem-resistant Enterobacteriaceae. J Med Microbiol 2013;62:1239-44

17. Eltai NO, Al Thani AA, Al-Ansari K, Deshmukh AS, Wehedy E, AlHadidi $\mathrm{SH}$, et al. Molecular characterization of extended spectrum beta-lactamases Enterobacteriaceae causing lower urinary tract infection among pediatric population. Antimicrob Resist Infect Control 2018;7:90

18. Elhassan MM, Hemeg HA, Ahmed AA. Dissemination of CTX-M extended-spectrum $\beta$-lactamases (ESBLs) among Escherichia coli and Klebsiella pneumoniae in Al-Madenah Al-Monawwarah Region, Saudi Arabia. Int J Clin Exp Med 2016;9:11051-7.

19. Al-Qahtani AA, Al-Agamy MH, Ali MS, Al-Ahdal MN, Aljohi MA, Shibl AM. Characterization of extended-spectrum beta-lactamaseproducing Klebsiella pneumoniae from Riyadh, Saudi Arabia. J Chemother 2014;26:139-45.

20. Alsultan AA, Amin TT. ESBL-producing E. coli and K. pneumoniae in Al-Ahsa, Saudi Arabia: Antibiotic susceptibility and prevalence of blaSHV and blaTEM. J Infect Dev Ctries 2013;7:1016-9.

21. Ahmed MA, Acharya A, Elmi AA, Hamid JM, Ahmed AM, Chandra P, et al. Antimicrobial susceptibility and molecular epidemiology of extended-spectrum betalactamase-producing Enterobacteriaceae from intensive care units at Hamad Medical Corporation, Qatar. Antimicrob Resist Infect Control 2016;5:4.

22. Alfaresi M, Sing GK, Senok A. First report of blaCTX-M-28 in Enterobacteriaceae isolates in the United Arab Emirates. J Pathog 2018;2018:1304793.

23. Alzahrania AK, Abbadia SH, Hassan MM, Gaberc A, AbdelMoneima AS. Antibiotic resistance profile and random amplification typing of $\beta$-lactamase-producing Enterobacteriaceae from the local area of A1-Taif and nearby cities in Saudi Arabia. Asian Biomed 2016;10:219-28

24. Hassan MI, Alzahrani AJ, Obeid OE, Khamis AH, Diab A. Detection of extended spectrum beta-lactamases-producing isolates and effect of AmpC overlapping. J Infect Dev Ctries 2013;7:618-29.

25. Leangapichart T, Dia NM, Olaitan AO, Gautret P, Brouqui P, Rolain JM. Acquisition of extended-spectrum beta-lactamases by Escherichia coli and Klebsiella pneumoniae in gut microbiota of pilgrims during the Hajj Pilgrimage of 2013. Antimicrob Agents Chemother 2016;60:3222-6.

26. Soliman MS, Wahid JB, Refaat KM. Phenotyping and molecular characterization of extended-spectrum beta-lactamases among clinical isolates of gram-negative bacilli in arar tertiary care Hospital, Saudi Arabia. J Commun Dis 2018;50:22-7

27. Somily AM, Arshad MZ, Garaween GA, Senok AC. Phenotypic and genotypic characterization of extended-spectrum b-lactamases producing Escherichia coli and Klebsiella pneumoniae in a tertiary care hospital in Riyadh, Saudi Arabia. Ann Saudi Med 2015;35:435-9.

28. Sonnevend A, Ghazawi A, Hashmey R, Haidermota A, Girgis S, Alfaresi M, et al. Multihospital occurrence of pan-resistant Klebsiella pneumoniae sequence Type 147 with an ISEcp1-directed blaOXA-181 insertion in the mgrB gene in the United Arab Emirates. Antimicrob Agents Chemother 2017;61:e0418-17

29. UzZaman T, Aldrees M,Al Johani SM, Alrodayyan M, Aldughashem FA, Balkhy HH. Multi-drug carbapenem-resistant Klebsiella pneumoniae infection carrying the OXA-48 gene and showing variations in outer membrane protein 36 causing an outbreak in a tertiary care hospital in Riyadh, Saudi Arabia. Int J Infect Dis 2014;28:186-92.

30. Al Sheikh YA, Marie MA, John J, Krishnappa LG, Dabwab KH. Prevalence of 16S rRNA methylase genes among beta-lactamaseproducing Enterobacteriaceae clinical isolates in Saudi Arabia. Libyan J Med 2014;9:24432.

31. Jamal WY, Albert MJ, Rotimi VO. High prevalence of New Delhi metallo-beta-lactamase-1 (NDM-1) producers among carbapenemresistant Enterobacteriaceae in Kuwait. PLoS One 2016;11:e0152638.

32. Al-Agamy MH, Shibl AM, Elkhizzi NA, Meunier D, Turton JF, Livermore DM. Persistence of Klebsiella pneumoniae clones with OXA-48 or NDM carbapenemases causing bacteraemias in a Riyadh hospital. Diagn Microbiol Infect Dis 2013;76:214-6.

33. Zowawi HM, Sartor AL, Balkhy HH, Walsh TR, Al Johani SM, Al Jindan RY, et al. Molecular characterization of carbapenemaseproducing Escherichia coli and Klebsiella pneumoniae in the countries of the Gulf cooperation council: Dominance of OXA-48 and NDM producers. Antimicrob Agents Chemother 2014;58:3085-90.

34. Alotaibi FE, Bukhari EE, Al-Mohizea MM, Hafiz T, Essa EB, Al Tokhais YI. Emergence of carbapenem-resistant Enterobacteriaceae isolated from patients in a university hospital in Saudi Arabia. Epidemiology, clinical profiles and outcomes. J Infect Public Health 2017;10:667-73

35. Al-Agamy MH, Aljallal A, Radwan HH, Shibl AM. Characterization of carbapenemases, ESBLs, and plasmid-mediated quinolone determinants in carbapenem-insensitive Escherichia coli and Klebsiella pneumoniae in Riyadh hospitals. J Infect Public Health 2018;11:64-8.

36. Ahn C, Butt AA, Rivera JI, Yaqoob M, Hag S, Khalil A, et al. OXA48-producing Enterobacteriaceae causing bacteremia, United Arab Emirates. Int J Infect Dis 2015;30:36-7.

37. Shahid M. Prevalence of CTX M extended-spectrum beta-lactamases in clinical gram-negative bacteria. Bahrain Med Bull 2014;36:228-31.

38. Hassan H AB. Molecular characterization of extended-spectrum betalactamase producing Enterobacteriaceae in a Saudi Arabian tertiary hospital. J Infect Dev Ctries 2014;8:282-8.

39. Bhaskar BH, Mulki SS, Joshi S, Adhikary R, Venkatesh BM. Molecular characterization of extended spectrum beta-lactamase and carbapenemase producing Klebsiella pneumoniae from a tertiary care hospital. Indian J Crit Care Med 2019;23:61-6.

40. Oteo J, Hernandez JM, Espasa M, Fleites A, Saez D, Bautista V, et al. Emergence of OXA-48-producing Klebsiella pneumoniae and the novel carbapenemases OXA-244 and OXA-245 in Spain. J Antimicrob Chemother 2013;68:317-21.

41. Guo L, An J, Ma Y, Ye L, Luo Y, Tao C, et al. Nosocomial outbreak of OXA-48-producing Klebsiella pneumoniae in a Chinese hospital: Clonal transmission of ST147 and ST383. PLoS One 2016;11:e0160754.

42. Shankar C, Mathur P, Venkatesan M, Pragasam AK, Anandan S, Khurana S, et al. Rapidly disseminating blaOXA-232 carrying Klebsiella pneumoniae belonging to ST231 in India: Multiple and varied mobile genetic elements. BMC Microbiol 2019;19:137.

43. Iraz M, Duzgun AO, Sandalli C, Doymaz MZ, Akkoyunlu Y, Saral A, et al. Distribution of beta-lactamase genes among carbapenem-resistant 
Klebsiella pneumoniae strains isolated from patients in Turkey. Ann Lab Med 2015;35:595-601.

44. Rossolini GM, D'Andrea MM, Mugnaioli C. The spread of CTXM-type extended-spectrum beta-lactamases. Clin Microbiol Infect 2008; 14 Suppl 1:33-41.

45. Paterson DL, Hujer KM, Hujer AM, Yeiser B, Bonomo MD, Rice LB, et al. Extended-spectrum beta-lactamases in Klebsiella pneumoniae bloodstream isolates from seven countries: Dominance and widespread prevalence of SHV-and CTX-M-type beta-lactamases. Antimicrob Agents Chemother 2003;47:3554-60.

46. Wang G, Huang T, Surendraiah PK, Wang K, Komal R, Zhuge J, et al. CTX-M beta-lactamase-producing Klebsiella pneumoniae in suburban New York City, New York, USA. Emerg Infect Dis 2013;19:1803-10.

47. Jemima SA, Verghese S. Multiplex PCR for bla(CTX-M) and bla(SHV) in the extended spectrum beta lactamase (ESBL) producing gramnegative isolates. Indian J Med Res 2008;128:313-7.

48. Sekar BS, Arunagiri K, Menaka K, Lalitha P, Aparna V. Detection and Characterization of bla CTX-M Gene by PCR-RFLP Analysis among Third Generation Cephalosporin Resistant Gram Negative Isolates. Proceedings of MICROCON 2006 XXX National Congress of Indian Association of Medical Microbiologists, 2006 October 27-29 OB-17. Nagpur: Government Medical College; 2006. p. 27.

49. Bevan ER, Jones AM, Hawkey PM. Global epidemiology of CTX-M $\beta$-lactamases: Temporal and geographical shifts in genotype. $\mathrm{J}$ Antimicrob Chemother 2017;72:2145-55
50. Ktari S, Arlet G, Mnif B, Gautier V, Mahjoubi F, Ben Jmeaa M, et al. Emergence of multidrug-resistant Klebsiella pneumoniae isolates producing VIM-4 metallo-beta-lactamase, CTX-M-15 extended-spectrum beta-lactamase, and CMY-4 AmpC beta-lactamase in a Tunisian university hospital. Antimicrob Agents Chemother 2006;50:4198-201

51. Dehshiri M, Khoramrooz SS, Zoladl M, Khosravani SA, Parhizgari $\mathrm{N}$, Motazedian $\mathrm{MH}$, et al. The frequency of Klebsiella pneumonia encoding genes for CTX-M, TEM-1 and SHV-1 extended-spectrum beta lactamases enzymes isolated from urinary tract infection. Ann Clin Microbiol Antimicrob 2018;17:4

52. Veeraraghavan B, Shankar C, Karunasree S, Kumari S, Ravi R, Ralph R. Carbapenem resistant Klebsiella pneumoniae isolated from bloodstream infection: Indian experience. Pathog Glob Health 2017;111:240-6.

53. Zhang X, Li X, Wang M, Yue H, Li P, Liu Y, et al. Outbreak of NDM1-producing Klebsiella pneumoniae causing neonatal infection in a teaching hospital in mainland China. Antimicrob Agents Chemother 2015;59:4349-51.

54. Liu Y, Wan LG, Deng Q, Cao XW, Yu Y, Xu QF. First description of NDM-1-, KPC-2-, VIM-2- and IMP-4-producing Klebsiella pneumoniae strains in a single Chinese teaching hospital. Epidemiol Infect 2015;143:376-84.

55. Falco A, Ramos Y, Franco E, Guzman A, Takiff H. A cluster of KPC2 and VIM-2-producing Klebsiella pneumoniae ST833 isolates from the pediatric service of a Venezuelan Hospital. BMC Infect Dis 2016;16:595. 